Available online at www.jmle.org

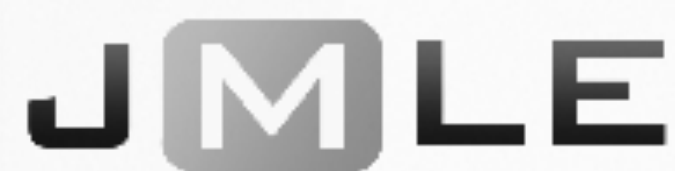

The National Association for Media Literacy Education's

Journal of Media Literacy Education 9 (2), 105 - 113

\title{
Voices in the Field \\ The Book Trailer Project: Media Production within an Integrated Classroom
}

\author{
Karen Festa \\ Narragansett Elementary School
}

\begin{abstract}
A special education co-teacher in an integrated elementary classroom describes key aspects of media literacy pedagogy for all students, including opportunities for critical analysis and creative media production. After elementary school students learned about author's craft, purpose, theme/message, three types of writing, and target audience, they began looking at these elements using Super Bowl ads and participated in rich discussions which demonstrated their analysis and reflection on advertising. Students created a book trailer project, working in small groups to create videos to promote a book written by a local author and illustrator. Such work bridges gaps in social-emotional development, communication skills, and critical thinking skills for all learners.
\end{abstract}

Keywords: digital literacy, media literacy, special needs, disabilities, children, elementary, school, book trailer

I have always worked with students who have special needs. As a special education teacher at Narragansett Elementary School, I have had the pleasure of working alongside a regular education teacher in a co-taught classroom. To elaborate, students with special needs are integrated with students in Grades 4 who are typically developing. The co-teacher Tonia Hassell and I share roles teaching all students in the classroom using differentiated instruction (Tomlinson \& McTighe, 2006), blended learning (Horn \& Staker, 2014), and universal design for learning (Rose \& Meyer, 2002). Our approach to academic service delivery depended on the individual needs of each student and ranged from small group instruction and 1:1 instruction, to pull-out instruction in a resource classroom. 
Classroom accommodations and modifications include support for social and emotional needs, support in all academic areas, peer interaction, speech and language skills, attention and executive function skills, technology supports (iPad, speech-to-text, text-to-speech, specific reading, writing, and math apps, writing frames, graphic organizers, etc.) and use of an FM system to support hearing impairment. During the 2014-2015 academic year, the co-teacher and I volunteered to participate in a digital literacy focus group professional development training and guidance program developed by the Media Education Lab at the University of Rhode Island.

\section{Analyzing Ads by Asking Critical Questions}

It was the week after the Super Bowl game when my co-teacher and I had planned a lesson to critically analyze selected commercials. Following the National Association for Media Literacy Education (NAMLE) Core Principles (NAMLE, 2007), we focused on teaching students how to analyze media by specifically the five critical questions of media literacy as presented on the Media Literacy Smartphone which include a focus on the author's purpose, how might others interpret the theme/message, what techniques the author used to attract and hold attention, whom is the intended target audience, and the author's craft (Hobbs, 2011). We selected three Super Bowl commercials from Coca Cola (2015) McDonald's (2015) and Reebok (2015) which we thought would generate an active discussion and require students to critically analyze the form and content of the advertising while providing evidence to support their opinions. The Media Literacy Smartphone was used with all students, and it served as a visual guide for students with special needs. The front of the smartphone was kid-friendly and clearly labeled with an image that all students were familiar with. This helped students with special needs to focus on a specific area. The back of the phone had five critical questions to guide students' thinking to critically analyze media; we also used the questions as a guide to frame our thinking.

My intended focus for students with special needs was to expose them to critical elements of media literacy in order to analyze and contribute to a discussion about the importance of using evidence to support opinions. I had no idea when planning the lesson that the students with special needs would exceed my intended focus and expectations. I was also unaware at the time that the students with special needs, specifically students with ADHD and cognitive learning disabilities, were not only motivated by the lesson, but also developing a deep curiosity about how to become digital media authors themselves, thus recognizing that media are a part of culture and function as agents of socialization and communication (NAMLE Core Principle 5). For example, when we focused on the question, "Who is the author and what is the purpose?" students were able to identify a possible target audience and the author and purpose. Additionally, students discussed techniques used to capture the viewer's attention. Tony and Mark (pseudonyms), two students with special needs, were intrigued by this discussion as it helped them bridge a connection between a media message and its purpose. They liked identifying techniques and dialogue within a media script that captures a viewer's attention. That same evening, Tony watched the commercial 
on his own and shared notes he wrote about it, citing specific examples which supported the author's craft to persuade viewers into purchasing product linking emotion with images and repetitive use of the product. Mark came into school the next day and shared a commercial he found which he felt was similar to the one we watched in class. We watched the video Mark shared and analyzed the commercial with the focus, "Who was the author and what is the purpose?" Without prompting, these children were clearly making connections between the classroom learning experience and their home viewing.

After the first week of analyzing and discussing Super Bowl commercials, the students had sparked an interest in commercials that had a positive message and messages which encouraged them to give back to the community. The class decided to hold a book drive called "Book it Forward." This project was similar to a shoe commercial we analyzed which donated shoes to those in need. As students watched their daily TV programs, they began to view commercials with a different lens, a closer lens perhaps, and took notes of those that interested them in a positive way. They shared these commercials with the class and we held deep discussions. For example, we analyzed and discussed the elements of a Jeep commercial which displayed "beautiful lands" and played specific music in the background. The students noticed specific areas in the world that were included in this commercial and discussed reasons why they were used. They also reviewed text which appeared at the end of the commercial and discussed why the author chose to include it. Additionally, we discussed how our feelings and emotions connected with the commercial and whether or not it was an effective way to engage the consumer.

We also researched some positive messages and actions within the commercials themselves. We used a commercial by Microsoft to analyze the language of empowerment: "We are going to empower every organization and every individual to do more and achieve more." We analyzed and discussed how this message was constructed. Tony explained, "Just because you have a disability does not mean you are unable to do the same things as others. You just have to do them differently and work harder." The stories and messages shared were driven by students' accounts of achieving their own personal goals and the difficulties they faced, yet overcame. These stores became so powerful and deep that Tonia and I were brought to tears in the classroom.

Tonia and I were both overwhelmed by the students' ability to hold deep conversations, ask thought-provoking questions, empathize and show care and concern for others, and be willing to help their own community as well as others across the globe. A drive to spread a positive message had been ignited in our classroom. It had become clear that the students were ready to dive in and they were yearning to create and film a media project. Tonia felt nervous about the project, wondering if the project would flop and whether instructional time would have been wasted. We sought out the support and filming expertise from Brien Jennings, the school's library media specialist. Tonia came to appreciate that the lessons students will learn and apply have the potential to stay with them through life. We were able to think flexibly, allow time for exploration, and apply many academic Common Core State Standards within the project itself. 


\section{Our First Media Project: Book Trailers}

Our first project was to have students create a book trailer. A local children's author Ashley Richer and local illustrator Ryan Maguire agreed to lend our class multiple copies of their 2014 book, Tyler's TALL Tales: Chasing the Moon and they were delighted our students were filming a book trailer about their book. Students were planning to create book trailers for younger students and the target audience was a first grade classroom in the building. After viewing the book trailers, they would meet the author and illustrator.

An authentic audience and a classroom within the school has many benefits. First, it allowed students opportunities for a real-life experience. Second, it allowed students to demonstrate learning with an intended purpose, and increased motivation and enthusiasm towards learning. By providing students opportunities for critical thinking, collaboration, communication, and creation, the students learned within a meaningful context (Partnership for 21st Century Learning, 2015). Also, it provided an opportunity for students to share and inspire the targeted audience, so they seek out the student "experts" for support and assistance. The author and illustrator gave us permission to use PDF images of the characters in the student-produced film. Our classroom buzzed with excitement when they started the project.

The book trailer format used in this lesson involves students performing in front of the camera while hand-drawn images appear behind them using green screen technology. We arranged for students to work in small groups of about 4-5 students. Students with special needs were paired with students who worked flexibly and supported one another as needed. They read through the book multiple times as a close read and asked questions to the author and illustrator. They also analyzed the text features, the meaning and purpose of illustrations, and the elements of the book such as theme, characters, character traits, purpose, audience, and setting.

Each lesson had one or two focus areas. For example, after reading the text multiple times, we looked at each illustration and had a discussion when looking at each individual page. We started with the question, "What does this illustration make you think of?" From there, we guided them with questions such as, "Why do you think the illustrator chose to use those colors? Are there any images that stand out to you? What captures your eye on this page? Why do you think the illustrator chose to include this image? How does this image connect with the text?"

Although the book itself was written for children ages five to eight, the students took their work very seriously and gave one hundred percent effort into the entire project. After students had analyzed the text, each group began to write a script. We had created a sample frame, a checklist of requirements to be included in the script and provided a storyboard just in case students needed scaffolding and organization for their ideas. Table 1 shows a checklist of requirements for the book trailer project.

We met with students while they were in the process of writing the script to ensure their script was clearly written for the target audience, did not give away 
the ending of the book, and included a short summary and a brief description of characters and the setting of the book. It took a bit of time for students to meet with us, calibrate their thinking so all were on the same page, and revise scripts. At times, students with special needs needed support in order to revise their thinking to coincide with the members of their group and communicate their ideas in a clear manner. We had to be flexible within our academic schedule, which was a minor bump in the road, but we were able to compensate.

Table 1

\section{Checklist of Requirements for the Book Trailer Project}

\section{Book Trailer: Tyler's Tall Tales}

Please place a check next to the guidelines that the trailer includes:

images match the script actors speak clearly... not too slow or fast the script has kid-friendly language the trailer includes character, setting and a quick peek into the plot the trailer ends with a hook to spark interest in reading the book

Students were allowed the freedom to design how and where they would film. Samantha (pseudonym), a student with a cognitive learning disability, drew pictures about the book. As Samantha described the pictures she drew, she was able to discuss the setting, character description, and a brief summary of the book all by looking at her drawings. She had difficulty writing down her thoughts, but her pictures were filled with detail and every detail she verbally explained had a specific meaning and purpose.

Timothy, a student in our class who was on the autism spectrum, did not want to be filmed on camera, but insisted on narrating the script. This came to us as quite a shock because on a daily basis, his verbal interactions are extremely limited (one to two sentences per day) and Timothy shares almost no eye contact with his peers and the staff. This project allowed Timothy an outlet for communication and had transformed the way he communicated with his teachers and peers. This also opened up a door for me as his special education teacher, as a new means for him to communicate, develop greater confidence, and share his thoughts and ideas with others. With the support of the library media specialist, the media center was used to film and edit the book trailers. There was only a small window of time available each week for each group to film and edit in the media center, which was another bump in the road, however we extended the date of our first viewing to allow students more time.

Table 2 shows a reflection sheet we used as part of the first viewing of the book trailer videos before the live audience. Students were asked to complete a peer review sheet including their classmates in each book trailer project as well as themselves. We used a three-pronged strategy that includes written and 
discussion-based feedback as well as teacher feedback (Payo, 2009). First, students completed a peer review sheet while viewing the book trailers. Then, after the book trailer had been viewed, the class held a candid discussion where they discussed strengths, highlights, suggestions, and lingering questions specific to the book trailer that was just viewed. Finally, after listening to the class discussion, students who were peer-reviewed were given a choice to sit, individually or in a small group, in a quiet setting to self-reflect and have an honest and candid discussion with a teacher. This approach allowed students a comfortable setting to informally express their thoughts, feelings, and next steps within their projects. During this process, students considered feedback from their peers and analyzed their information in order to plan any revisions to the book trailers before a live audience. This peer review process and three-pronged strategy allowed students to be in control of their learning, analyze the task and synthesize peer review suggestions related to their media production, and brainstorm next steps before finalizing their book trailer.

Table 2

\section{Book Trailer Reflection}

My experience throughout the book trailer project was:

My favorite part was:

I thought was challenging because

One thing I'd suggest is:

One think I'd like to consider is:

A suggestion for next year would be:

The assembly program included two phases. First, the author and illustrator sat with the student media makers and watched each book trailer. They had smiles on their faces the entire time. After the viewing, the author and illustrator shared positive feedback about each book trailer. They asked students questions related to their project and the students asked them questions related to the book.

After a 20-minute Q\&A session, the first grade children arrived for the second phase of the assembly program. You could feel the excitement within the classroom. As the first grade children watched the book trailers, they laughed, they smiled, they cheered, they gasped with amazement, and they clapped after each and every book trailer. Figure 2 shows photographs from the event. They shared positive feedback with the class and seemed to truly embrace the studentcreated book trailers. 
Students gained confidence and a sense of pride from responding to questions from the younger children. For example, Caroline, who had dyslexia, was answering the question of a first grader about how she analyzed the images of the story in order to create a script and film using images from the book. Caroline stood proud and confident. The first grade teacher told us after the experience that she was impressed by the level of detail, creativity, and media production from each of the students. She could feel the students' positive energy and sense of pride that day. She also told us that her students were inspired to create their own storyboards and create a book trailer. It was a day we will never forget.
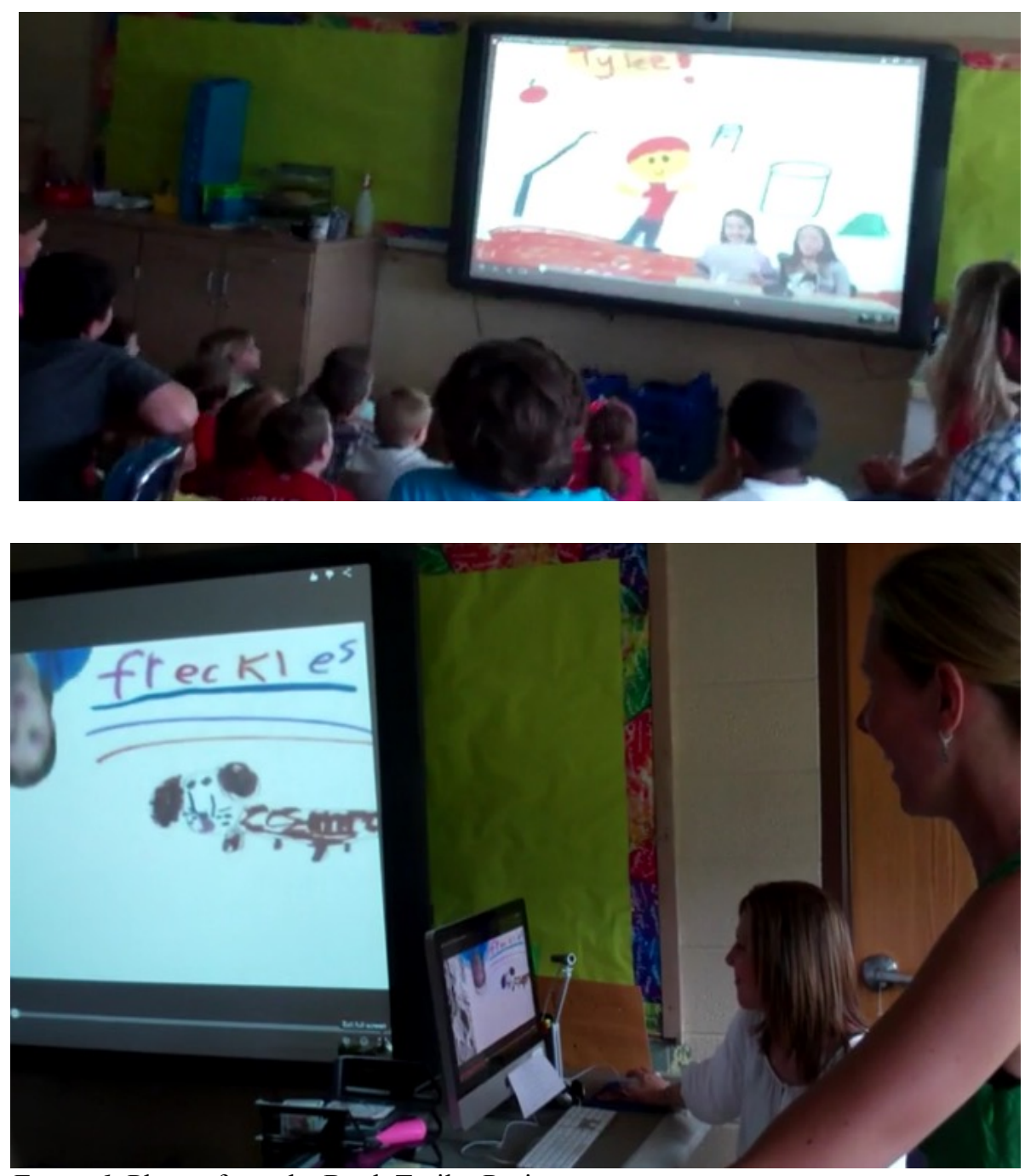

Figure 1. Photos from the Book Trailer Project

Collectively, our class and I also learned from some bumps in the road. As we had difficulties related to scheduling, timing and groups calibrating their ideas, the students with special needs were our biggest cheerleaders. They may not always have the most accurate answers when asked by the group to express their ideas and opinions related to the book, but they worked hard to understand the members of their group and communicate their ideas more clearly. They were 
able to self-reflect and navigate their own individual paths of learning. They were able to establish roles within a group where they could contribute to a larger product which would be shared with adults and peers. They were able to receive feedback and make decisions that would improve their final product.

\section{Significance}

Exposure to a digital and media literacy professional development learning experience helped spark ideas within me that enabled me to take risks with students all while promoting a growth mindset and problem solving as a classroom community. My co-teacher and I took what we had learned and revised our thinking to continue on with more media projects that activated deeper learning. We continued to develop leadership as we connected with other grade level teachers in our school and shared our learning with the community on Digital Learning Day, an annual event organized by the Washington DC nonprofit organization, Alliance for Excellent Education.

Since then, I have co-moderated chats on Twitter with topics related to digital media literacy, the power of positivity, universal design for learning, and motivating and engaging all students. (You can follow me throughout my educational journey on Twitter @ teach4spclneeds.) Tonia and I inspired teachers and classrooms to take risks and learn alongside our students by creating more book trailers using an iPad app and sharing them on YouTube and on our own school website, and by presenting a class debate for Kindergarten students and school staff using the Buncee digital canvas platform. Learning from our mistakes and taking risks are never a waste of time. Instead, they create real-world opportunities to solve complex problems and celebrate growth and achievements. Students and teachers greatly benefit from opportunities to dive into digital and media literacy. They help us make informed decisions as consumers and producers of digital and media products.

Perspective taking, flexible thinking, reflection, and recognizing people's purpose and point of view are life skills which have the potential to benefit all children. Allowing students with special needs to think critically while collaborating with peers through a hands-on creative learning approach could decrease anxiety and relieve pressures they might be feeling related to academics. Students with special needs learn to navigate their own paths towards success while working collaboratively alongside their peers. They contribute to group discussions and make team-based decisions which impact themselves as well as their finished product. Imagine the growth and confidence students will feel while reflecting on their finished product and sharing it with others.

Taking a leap to try something new and learn alongside our students was incredibly amazing. I am fortunate to have been able to follow each and every student's journey throughout the process of the book trailer project. In fact, Tonia and I were so inspired that we started filming our own "teacher talk" videos (Festa $\&$ Hassell, 2015). We used them to introduce new units of study, send positive messages, and model a mini debate. We're not fancy: we had a colleague videotape us using an iPhone and we uploaded directly to YouTube. The students loved it, and it was a positive and fun way to spark interest and enthusiasm for 
learning. My best advice is to think flexibly, be open to new ideas, and let the students drive the learning. You will be amazed by how your students communicate, collaborate, and critically analyze media.

\section{Application}

- Be Flexible. Provide students the flexibility to produce media in a form that they feel best suits their individual strengths and needs.

- Take Time. Students need time to build knowledge and skills. Allow time and freedom for students to create and design a real-life product.

- Create Opportunities for Sharing and Feedback. Provide opportunities for peer review and a safe space for students to reflect and discuss with a teacher allows students with special needs opportunities to analyze their own strengths and weakness and revise their thinking.

\section{References}

Coca Cola. (2015). Make It Happy. Retrieved from

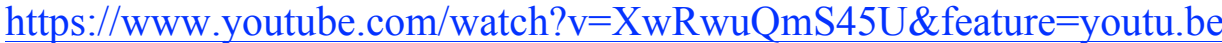

Festa, K., \& Hassell, T. (2015). Teacher Talk. YouTube Series. Retrieved from https://www.youtube.com/user/shireyk21

Hobbs, R. (2011). Digital and media literacy: Connecting culture and classroom. Thousand Oaks, CA: Corwin.

Horn \& Staker. (2014). Blended: Using disruptive innovation to improve schools. San Francisco, CA: Jossey-Bass.

McDonald's. (2015). Pay With Lovin'. Retrieved from https://www.youtube.com/watch?v=RsogFwyDACY\&feature=youtu.be

Media Education Lab. (2013). Power Voices for Kids. Retrieved from http://www.discovermedialiteracy.com

National Association for Media Literacy Education. (NAMLE) (2007). Core principles of media literacy education in the United States. Retrieved from https://namle.net/publications/core-principles/

Partnership for 21st Century Learning. (2015). The 4 C's Research Series. p21.org. Retrieved from http://www.p21.org/our-work/4cs-research-series

Payo, R. (2009). ADHD: Current Research and Teaching Strategies for Reading and Writing. Retrieved from http://beyondpenguins.ehe.osu.edu/issue/keeping-warm/adhd-currentresearch-and-teaching-strategies-for-reading-and-writing

Reebok. (2015). Be More Human. Retrieved from https://www.youtube.com/watch?v=olPj2kh-SD0\&feature=youtu.be

Richer, A., \& Maguire, R. (2014). Tyler's TALL tales: Chasing the moon. Charleston, SC: Tyler's TALL Tales.

Rose, D. H., \& Meyer, A. (2002). Teaching every student in the digital age: Universal design for learning. Alexandria, VA: Association for Supervision and Curriculum Development (ASCD).

Tomlinson, C. A., \& McTighe, J. (2006). Integrating differentiated instruction \& understanding by design: Connecting content and kids. Alexandria, VA: Association for Supervision and Curriculum Development (ASCD). 